\title{
Impact of sensitization workshop on knowledge and awareness of hospital-acquired infection among nurses of a teaching hospital in India
}

\author{
Shubhada Avachat ${ }^{1}$, Deepak Phalke ${ }^{2}$, Mrinal Zambare ${ }^{3}$, Vaishali Phalke ${ }^{4}$ \\ ${ }^{1}$ Associate Professor, ${ }^{3}$ Professor and Head; Department of Preventive and Social Medicine, Padmashri Dr. Vitthalrao Vikhe \\ Patil Foundation Medical College, Ahmednagar, India. ${ }^{2}$ Professor and Head, ${ }^{4}$ Professor, Department of Preventive and Social \\ Medicine, Rural Medical College, Loni, India.
}

\begin{abstract}
Hospital-acquired infection (HAI) in healthcare settings is the most frequent adverse event in healthcare delivery worldwide. Hundreds of millions of patients are affected by HAI worldwide each year, leading to significant patient mortality rates and financial losses for health systems. We evaluated the impact of a sensitization workshop on knowledge and awareness of HAI among nurses in a medical college hospital in rural area of Ahmednagar district, India from March 2010 to August 2010. One hundred staff nurses, who had more than one year of experience, had attended the workshops on HAI. Pre- and post-test data was collected by a questionnaire. A significant increase in number of nurses having knowledge regarding commonly occurring HAI and routes of transmission, barrier nursing and hygienic hand washing techniques, hospital waste management (its importance and color coding), and the importance of an infection control team was observed after the workshop. Education and training of healthcare workers about standard infection control can reduce the extent of risks of HAI. Nurses have a critical role to play in prevention measures and infection control and they should have the opportunity for continuous professional development.
\end{abstract}

Keywords: Hospital-acquired infection, Nurses, Training workshop, Knowledge, India.

\section{Introduction}

Hospital-acquired infection (HAI) or healthcareassociated infection (HAI), or nosocomial infection acquired in healthcare settings are the most frequent adverse events in healthcare delivery worldwide. ${ }^{1,2}$ HAI affects patients in a hospital or other healthcare facility, and are not present or incubating at the time of admission. ${ }^{1}$ They include infections acquired by patients in the hospital or facility but only showing symptoms after discharge. ${ }^{2} \mathrm{HAI}$ also includes occupational infections among healthcare staff. Hundreds of millions of patients are affected by HAI worldwide each year, leading to significant patient mortality rates and financial losses for health systems. ${ }^{1,2}$ Of every 100 hospitalized patients at any given time, 7 in developed countries, and 10 in developing countries will acquire at least one HAI. ${ }^{3}$ The prevalence of HAI in developed countries varies between $5 \%$ and $15 \%{ }^{5}$ and it varies between $5.7 \%$ and $19.1 \%$ in low- and middleincome countries. ${ }^{3}$

HAI takes a heavy toll on patients and their families by causing illness, prolonging hospital stays, reducing the quality of life, increasing the potential of disabilities, increasing the resistance of the microbes to antimicrobials, as well as leading to excess costs and sometimes death of the patient. ${ }^{1,4}$ Spread of HAI serves as a major source of worry for managers in the healthcare practice, particularly in the resource poor healthcare settings of developing

\section{Practice Points}

- Hospital-acquired infection (HAI) in healthcare settings is the most frequent adverse event in healthcare delivery worldwide.

- HAI causes prolonged hospital stay, reducing quality of life, potential disability, increasing resistance to antimicrobials, excess costs and sometimes death.

- Education and training of healthcare workers about standard infection control can reduce the extent of risks of HAI.

- A significant increase in knowledge regarding was observed among nurses after the workshop regarding HAI and routes of transmission, barrier nursing and hand washing techniques, hospital waste management, and importance of infection control team.

- Nurses have a critical role to play in prevention and infection control and they should have scopes for continuous professional development.

countries. ${ }^{1,4}$ Hospitals provide a favorable transmission pathway for the spread of HAI, owing partly to poor infection control practices among health workers on

Correspondence: Dr. Shubhada Avachat, 5, Samartha colony Bhutkarwadi, Savedi Road, Ahmednagar Maharashtra 414003, India. E-mail: shubhadasunil@gmail.com. 
one hand, and overcrowding of patients in most clinical settings on the other. ${ }^{1,4,5}$ We evaluated the impact of a sensitization workshop on knowledge and awareness of HAI among the nurses of a teaching hospital in India.

\section{Materials and methods}

The study was conducted in a medical college hospital in the rural area of the Ahmednagar district from March 2010 to August 2010. One hundred staff nurses (who had at least one year of experience) were selected by simple random sampling to attend workshops on HAI. Pre- and post-test data was collected by a questionnaire, which was developed according to the international infection control guidelines. ${ }^{6}$ The questionnaire consisted of closed and open ended questions and included questions on nosocomial infection, universal precautions and hand hygiene, and hospital waste management. In the workshop, demonstrations, videos, and lectures were arranged to impart the knowledge and increase awareness. The responses were recorded onto the computer using the statistical software SPSS and analyzed. Percentages and proportions were used, and the chi-square test was used to find any significance.

\section{Result}

The knowledge and awareness of participants on HAI before and after the workshop are shown in Fig 1. Out of 100 nurses, only $31 \%$ nurses identified that urinary tract and respiratory tract infections are common HAI, and $64 \%$ mentioned correctly the commonest routes of transmission of HAI prior to workshop. However, after the workshop percentage of nurses having correct knowledge regarding commonly occurring $\mathrm{HAI}$ and routes of transmission increased to $91 \%$ and $94 \%$ respectively. Prior to the workshop only $70 \%$ nurses had the correct knowledge regarding barrier nursing and hygienic hand washing techniques. However after the workshop, significant improvement was observed among the nurses $(96 \%)(p<0.001)$. A significant increase in the number of nurses having knowledge regarding hospital waste management (its importance and color coding) was observed after the workshop $(p<0.001)$. The number of nurses having knowledge regarding universal precautions, common disinfection and sterilization procedures carried out in the wards increased after the workshop. We also found that $62 \%$ of nurses opined that an infection control team is needed for the control of HAI prior to the workshop but a significantly higher number of nurses (95\%) realized the importance of the infection control team after the workshop $(\mathrm{p}<0.001)$.

\section{Discussion}

Education and training of healthcare workers about standard infection control, as well as strict adherence by healthcare staff and students to aseptic practice, can reduce the extent of risks of HAI. ${ }^{1,5}$ Like our study, other studies in India, ${ }^{7,8}$ Italy $^{9}$ and Ghana ${ }^{10}$ identified the nurses' and healthcare students' lack of knowledge regarding HAI. Hand hygiene has always been considered one of the cornerstones of infection control, but adherence to recommendations for hand-hygiene practices remains extremely low in most healthcare settings. ${ }^{11}$ Strict adherence to universal precautions is a crucial measure to prevent HAI. Knowledge regarding standard infection control practices and universal precautions improved significantly in our study and other studies also mentioned a similar finding. Hospital waste is one of the most important sources of HAI; hence, proper handling of hospital waste is essential. Nurses are the key persons as far as handling of sharps and infectious waste is concerned, therefore nurses must understand

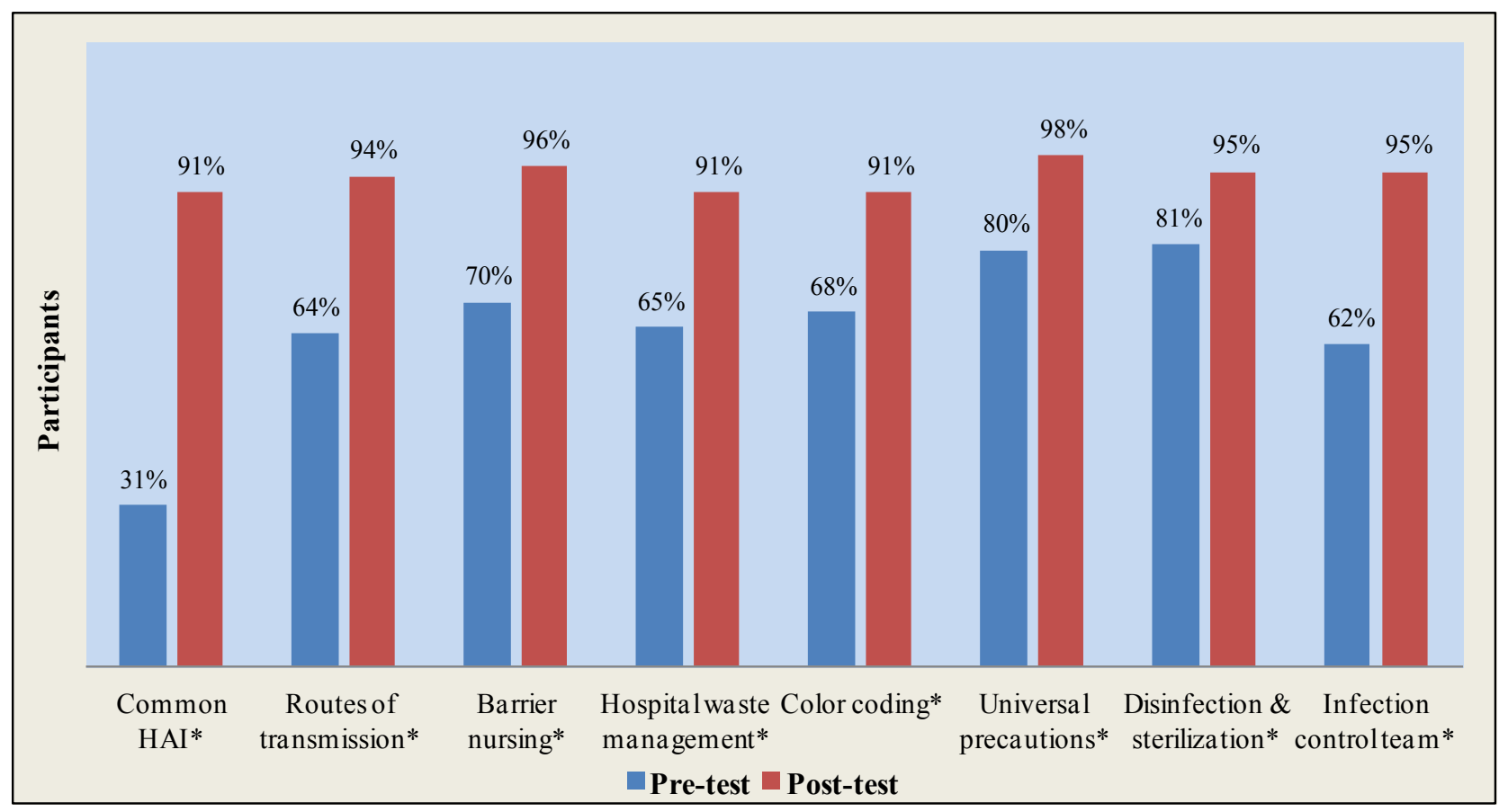

Fig 1: Knowledge and awareness of participants on HAI before and after the workshop

*Values are significant at $p<0.05$. 
the role of hospital waste management in the prevention of HAI. Similar to our study, another study also mentioned the significant improvement in knowledge regarding hospital waste management after the training of health workers. ${ }^{7}$ An infection control team plays a vital role in the prevention of HAI in the healthcare setting. Among the healthcare workers, nurses have a critical role to play in the prevention measures and infection control and they should have opportunity for continuous professional development. Suchitra et al. ${ }^{12}$ emphasized that educational intervention on HAI had positive impact on knowledge and awareness of nursing staff.

\section{Conclusion}

Knowledge about various aspects of HAI among nurses in the teaching hospital was significantly improved after they attended a training workshop. Renewed effort geared towards education in terms of training and retraining of healthcare workers about HAI as it is shown that standard infection control measures can reduce the extent of risks of HAI in healthcare settings.

\section{Acknowledgement}

Authors are grateful to management of Pravara Medical Trust for their permission to conduct the research. We are also thankful to Medical Superintendent and resource persons from Microbiology Department and Nursing College for their contribution in the workshop and third year medical students for their help in data collection.

\section{References}

1. WHO. Prevention of hospital-acquired infections: a practical guide. Geneva: World Health Organization, 2002.

2. Burke JP. Infection control - a problem for patient safety. N Engl J Med 2003;348:651-6.

3. WHO. Health care-associated infections. Fact sheet. http://www.who.int/gpsc/country work/ gpsc ccisc fact sheet en.pdf (accessed August 2012)
4. WHO. WHO guidelines on hand hygiene in health care. Geneva: World Health Organization, 2009.

5. Samuel SO, Kayode OO, Musa OI. Nosocomial infections and the challenges of control in developing countries. Afr $J$ Clin Exp Microbiol 2011;11:102-10.

6. Tavolacci MP, Ladner J, Bailly L. Prevention of nosocomial infection and standard precautions: knowledge and source of information among healthcare students. Infect Control Hosp Epidemiol 2008;29:642-7.

7. Vij A, Williamson SN, Gupta S. Knowledge and practice of nursing staff towards infection control measures in a tertiary care hospital. J Acad Hosp Admin 2001;13:31-5.

8. Jain M, Dogra V, Mishra B, Thakur A, Loomba PS. Infection control practices among doctors and nurses in a tertiary care hospital. Ann Trop Med Public Health 2012;5:29-33.

9. Sessa A, Giuseppe G, Albano L, Angelillo I. An investigation of nurses' knowledge, attitudes, and practices regarding disinfection procedures in Italy._BMC Infect Dis 2011:11:148.

10. Bello AI, Asiedu EN, Adegoke BO, Quartey JN, Appiah-Kubi KO, Owusu-Ansah B. Nosocomial infections: knowledge and source of information among clinical health care students in Ghana. Int J Gen Med 2011;4:571-4.

11. Pittet D. Mourouga P., Perneger T.V. Infection Control Program. Compliance with handwashing in a teaching hospital. Ann Intern Med 1999;130:126-30.

12. Suchitra JN, Lakshmi Devi. Impact of education on knowledge, attitudes and practices among various categories of health care workers on nosocomial infections. Indian J Med Microbiol 2007;25:181-7. 